\title{
DINÁMICA INDUSTRIAL, PLANTEAMIENTO Y ORDENACIÓN DEL TERRITORIO EN EL MUNICIPIO DE LORCA (MURCIA, SURESTE DE ESPAÑA)
}

\author{
Joaquín David Romera Franco \\ Universidad de Murcia
}

\section{RESUMEN}

Lorca es una ciudad de tamaño medio que, por su localización estratégica en el corredor Mediterráneo, ofrece diferentes oportunidades de negocio. Tradicionalmente la actividad industrial ha ocupado un lugar secundario en la economía local en relación a otros sectores productivos que han acaparado la mano de obra y la riqueza generada. A pesar de ello, resulta muy notable el impacto que las actividades industriales tienen en el espacio urbano y periurbano de Lorca, encontrando tipologías de localización muy diversas que responden a intereses empresariales y a la planificación y práctica urbanística llevada a cabo en el municipio. A sectores industriales maduros en franca decadencia, se han unido otros más modernos en fase de expansión.

Como en otras ocasiones, la industria, en este momento de aguda crisis económica internacional, tampoco tiene capacidad en Lorca para absorber la mano de obra excedente de otros sectores, lo cual no satisface la imperiosa necesidad de diversificar y modernizar con nuevas alternativas el tradicional modelo económico lorquino.

Palabras clave: actividad industrial, población activa, planificación urbana, impacto territorial, estrategias de localización industrial, Lorca.

\section{SUMMARY}

Lorca is a city of average size that, for his strategic location in the Mediterranean corridor, offers different opportunities of business. Traditionally the 
industrial activity has occupied a secondary place in the local economy in relation to other productive sectors that have monopolized the workforce and the generated wealth. In spite of it, there turns out to be very notable the impact that the industrial activities have in the urban space of Lorca, thinking types of location very diverse that they answer to managerial interests and to the planning and urban development practice carried out in the municipality. To industrial mature sectors in decadence, more modern others have joined in phase of expansion.

Since in other occasions, the industry, at this moment of economic international crisis, does not also have aptitude in Lorca to absorb the excessive workforce of other sectors, which does not satisfy the imperious need to diversify and modernize with new alternatives the traditional economic local model.

Keywords: industrial activity, population activates, town planning, territorial impact, strategies of industrial location, Lorca.

\section{INTRODUCCIÓN}

El municipio de Lorca ocupa toda la zona suroccidental de la Región de Murcia (Sureste de España). Es el segundo más extenso del Estado (1.675,2 $\mathrm{km}^{2}$, el 15\% del territorio regional) y está poblado por 92.694 habitantes (INE, 2010), siendo uno de los vértices que junto a Murcia y Cartagena forman el tradicional triángulo urbano murciano (Roselló, 1982). La ciudad de Lorca, además de ser un importante centro agrícola y ganadero, es capital comercial y de servicios de una amplia comarca natural que se prolonga hacia el interior de las provincias de Almería y Granada debido a sus funciones urbanas y a su emplazamiento estratégico en el Valle del Guadalentín. Ello le ha supuesto cumplir en un amplio espacio el papel de Capital Subregional (Capel, 1968), papel cada vez más diluido por la mayor dotación funcional de los municipios de su área de influencia, el desarrollo del estado de las autonomías y la competencia que ejercen otros centros urbanos. Como se verá, el sector industrial cumple un papel secundario en la economía local en términos de empleo y producción aunque en los últimos años se han puesto en marcha importantes iniciativas para impulsar el sector y favorecer el asentamiento ordenado de nuevas empresas, cuyo impacto en el territorio es cada vez mayor.

El escritor Torbado (1994), en su visita a Lorca, deja constancia en su crónica, del pintoresco mosaico estático que presentaba la periferia de la ciudad tras una etapa de efervescencia económica: «Este desarrollo ha ido 
trayendo ininterrumpidamente a la ciudad y a sus inmediaciones los emplazamientos fabriles de los más variopintos productos: cementos, metalistería, cerámicas, chacinería, curtidos... Como no podía ser menos, todo este abigarramiento industrial ha marcado su impronta en el paisaje urbano y suburbano. Este último, aparece cuajado de fábricas, naves, talleres, escombreras, humos, desechos, postes de alta tensión, cables, polvo, almacenes, canteras; todo en un insospechado desorden que parece funcionar con cierto orden». Desde entonces, el paisaje suburbano de Lorca (como en toda ciudad) ha cambiado mucho: se han tratado de corregir los problemas urbanísticos y medioambientales que genera la industria desordenada, se ha potenciado el sector en la medida de lo posible y se han creado nuevas infraestructuras y polos de desarrollo industrial, alguno de los cuales (Saprelorca) llega a tener lo que Mas (1999) denomina como «imagen de marca» por su buena gestión, disposición de parcelas, ventajas de localización y servicios a las empresas.

\section{INDUSTRIA LORQUINA Y RECURSOS HUMANOS}

El sector industrial en Lorca es poco empleador porque no estamos ante una ciudad industrial. Según los datos del último censo oficial de 2001 (INE, 2004), la población ocupada en aquel entonces en Lorca era de 33.980 trabajadores, de los que 5.230 estaban empleados en el sector industrial, es decir, el 15,4\% del total (19\% en la Región de Murcia y 18\% en España); un 96,2\% lo hacía en empresas manufactureras. Durante la década de los noventa el peso específico de la industria local disminuyó en algo más de cuatro puntos (19,5\% de los activos en 1991) ante el mayor dinamismo de los sectores agrario, de la construcción y servicios, aunque en términos absolutos, la población ocupada aumentó en más de 1.200 personas (CARM-Consejería de Fomento y Trabajo, 1994).

Para obtener una información más reciente, se cuenta con los datos de afiliación a la Seguridad Social por sectores económicos (CARM-Servicio Regional de Empleo y Formación, 2010). En ellos se comprueba el escaso peso de la industria en la economía lorquina al aglutinar a sólo el 8,73\% de los afiliados totales; el sector servicios acoge a la mitad de los trabajadores de Lorca y el agrario a algo más de la tercera parte (Cuadro 1). La situación se repite si se tiene en cuenta la distribución de las empresas afiliadas a la Seguridad Social, siendo igualmente las de los sectores servicios y agrario las predominantes. 
Cuadro 1: Número de afiliados (trabajadores y empresas) a la Seguridad Social por sectores económicos en Lorca y la Región de Murcia (2010)

\begin{tabular}{|l|c|r|r|r|r|r|}
\hline \multirow{2}{*}{$\begin{array}{c}\text { Sector } \\
\text { económico }\end{array}$} & \multicolumn{2}{|c|}{ Lorca } & \multicolumn{1}{c|}{ Región } & \multicolumn{2}{c|}{ Lorca } & Región \\
\cline { 2 - 7 } & Afiliados & \multicolumn{1}{c|}{$\%$} & \multicolumn{1}{c|}{$\%$} & Empresas & \multicolumn{1}{c|}{$\%$} & $\%$ \\
\hline Agrario & 11.142 & 33,80 & 14,82 & 428 & 13,17 & 8,19 \\
\hline Industrial & 2.877 & 8,73 & 13,25 & 264 & 8,13 & 9,95 \\
\hline Construcción & 2.834 & 8,60 & 9,13 & 398 & 12,25 & 11,55 \\
\hline Servicios & 16.108 & 48,87 & 61,80 & 2.159 & 66,45 & 70,31 \\
\hline Total & 32.961 & 100,00 & 100,00 & 3.249 & 100,00 & 100,00 \\
\hline
\end{tabular}

Fuente: Servicio Regional de Empleo y Formación (SEF). Centro de Datos.

En los últimos quince años, la estructura productiva de Lorca ha sufrido un proceso de transformación importante, de tal suerte que sectores económicos tradicionales muy potentes como la industria textil o la del curtido han perdido buena parte de su fuerza laboral; por el contrario, sectores emergentes hasta 2008 como la construcción, las actividades inmobiliarias o el desarrollo de empresas de servicios personales y a las empresas, han derivado a la economía local por razones de dependencia a una situación de gran vulnerabilidad que afecta a toda una sociedad, alcanzándose una cifra de desempleados récord superior a los 7.500 parados (2.100 en 2005). En este contexto de grave crisis económica, se ha puesto de manifiesto cómo la economía de Lorca adolece de un sector industrial diversificado y competitivo que absorba el excedente laboral de los sectores de la construcción y servicios, papel que cumplen en la actualidad las actividades agrarias que vuelven a convertirse nuevamente en eje dinamizador de la economía lorquina. Los datos del Observatorio Ocupacional del SEF lo dejan bien claro: entre 2005 y 2010 el único sector al alza en cuanto a número de afiliados a la Seguridad Social es el agrario con un crecimiento del 11,4\% (+1.147); en cambio, la construcción es el sector que más afiliados pierde con un descenso del 59\% (1.674 empleados menos) mientras el sector servicios cae un moderado 7,8\% (-1.272). En 2010 la producción agraria de la comarca aumentó un $10 \%$ respecto al año anterior (COAG, 2011).

El descalabro en la industria también es muy significativo. En los últimos cinco años, el empleo aquí ha descendido un 25\%, con la pérdida de casi 1.000 trabajadores. En algunos subsectores como el textil o el curtido la sangría de puestos de trabajo supera el $60 \%$ con el cierre de varias fábricas de curtidos o de empresas de la confección tan significativas como «Lorca Industrial» que llegó a emplear a 400 personas, por políticas de deslocalización. No es nada 
arriesgado pensar que Lorca esté sufriendo en estos sectores clave la mayor desindustrialización de los últimos sesenta años, cuando se vino abajo la industria alpargatera (Gil, 1969). El profesor Aranda (2010) deja claro que el industrial es uno de los pilares productivos más afectados por la crisis actual: «La industria manufacturera de Lorca ha sido el claro perdedor en esta etapa expansiva, con una reorientación, en buena parte, hacia actividades con escasa capacidad de sostenimiento y muy sujetas a las fluctuaciones del mercado y la demanda». Las ramas industriales más afectadas son las del curtido, textil y confección, calzado, marroquinería, cárnicas, alimentación animal y materiales de la construcción. No se ha sabido aprovechar la variada producción agraria para después ser transformada (conservas) y tampoco cerrado algunos ciclos productivos industriales (por ejemplo, el desarrollo de una potente industria del calzado o del sector cárnico). En una publicación reciente (Fundación BBVA, 2010) se muestra que los niveles de innovación y economía del conocimiento en esta ciudad están muy por debajo respecto a otros municipios españoles de similares características: apenas el 0,37\% del empleo en empresas de alta tecnología se concentra en la industria, sólo el $14 \%$ de los activos están empleados en actividades innovadoras; 23 de cada 1.000 empresas lorquinas tiene certificado de calidad y 1,5 de cada 1.000 exporta sus productos al exterior. Igualmente, entre 2000 y 2005 las inversiones en alta tecnología en Lorca fueron muy escasas si se comparan con las de otros municipios de tamaño medio, lo que debe hacer reflexionar a autoridades y agentes sociales si se quiere construir una sociedad dinámica y avanzada a través de reformas estructurales (léase un cambio de modelo productivo), o quedar rezagada a un segundo plano, como viene siendo hasta ahora.

El peso de la industria de Lorca en el conjunto de la Región de Murcia está en consonancia con su volumen demográfico y capacidad económica según el Anuario Económico de España (2010). El número de actividades industriales y de la construcción está cuantificado en 1.246, lo que supone el $6,1 \%$ del conjunto regional, siendo el municipio que mayor crecimiento ha ostentado desde 2004 (Cuadro 2). Por su parte, el índice industrial para Lorca supone el 7,6\% del autonómico y la suma de su actividad económica, el 6,1\%. Destaca igualmente el peso específico que tienen las tres grandes ciudades murcianas al concentrar el 51\% de la población, el $47 \%$ de las actividades industriales, el 66\% del índice industrial y el 56\% de la actividad económica. 
Cuadro 2: Actividades industriales en los municipios mayores de 30.000 habitantes en la Región de Murcia (2010)

\begin{tabular}{|l|c|c|r|r|r|}
\hline Municipio & $\begin{array}{c}\text { Población } \\
2010\left(^{*}\right)\end{array}$ & $\begin{array}{c}\text { Actividades } \\
\text { industriales y } \\
\text { construcción }\end{array}$ & $\begin{array}{c}\text { Variación } \\
2004-2009 \\
(\%)\end{array}$ & $\begin{array}{c}\text { Índice } \\
\text { industrial }\end{array}$ & $\begin{array}{c}\text { Índice } \\
\text { actividad } \\
\text { económica }\end{array}$ \\
\hline Murcia & 441.345 & 5.957 & 14,1 & 648 & 732 \\
\hline Cartagena & 214.165 & 2.326 & 16,8 & 983 & 613 \\
\hline Lorca & 92.694 & 1.246 & 19,2 & 215 & 165 \\
\hline Molina de S. & 65.815 & 936 & 14,5 & 131 & 109 \\
\hline Alcantarilla & 41.326 & 603 & $-3,6$ & 59 & 54 \\
\hline Mazarrón & 35.464 & 428 & 9,9 & 12 & 35 \\
\hline Cieza & 35.385 & 416 & $-9,8$ & 23 & 31 \\
\hline Yecla & 34.945 & 958 & $-0,7$ & 111 & 65 \\
\hline Águilas & 34.900 & 417 & $-7,2$ & 17 & 32 \\
\hline $\begin{array}{l}\text { Torre- } \\
\text { Pacheco }\end{array}$ & 32.471 & 503 & 10,0 & 24 & 46 \\
\hline San Javier & 31.820 & 411 & $-4,3$ & 19 & 43 \\
\hline Región & 1.461 .979 & 20.257 & 6,4 & 2.800 & 2.704 \\
\hline
\end{tabular}

Fuente: Anuario Económico de España (2010). La Caixa. (*) Instituto Nacional de Estadística.

\section{EL PLANEAMIENTO INDUSTRIAL EN LORCA}

El planeamiento industrial en Lorca, hasta fechas recientes, ha resultado poco efectivo como consecuencia de la aprobación y aplicación de unos planes de ordenación muy conservadores en los que no se apostaba por el desarrollo industrial de la ciudad, al menos de una forma ordenada, funcional y equilibrada. La planificación y práctica urbanística ha estado durante más de cuarenta años centrada en la capitalidad, obviando la ordenación en la periferia toda vez que se producía la expulsión de las actividades industriales de la trama urbana al entorno de las principales vías de comunicación y se iniciaba la aparición dispersa de muchas fábricas en la zona rural próxima.

El primer Plan General de Ordenación Urbana (PGOU) se redactó, de forma tardía, en 1952 por los arquitectos Blein y Carbonell. Aunque nunca llegó a estar en vigor, en él se preveían amplias zonas industriales en las salidas principales de la ciudad en dirección a Granada y Murcia, y junto a las estaciones de ferrocarril (Figura 1). Apostaba por sacar las fábricas del industrioso barrio de San Cristóbal a fin de sanearlo y crear junto a él la mayor 
Figura 1: Reutilización de antiguas fábricas de finales del siglo XIX en el centro de Lorca junto a la estación de ferrocarril

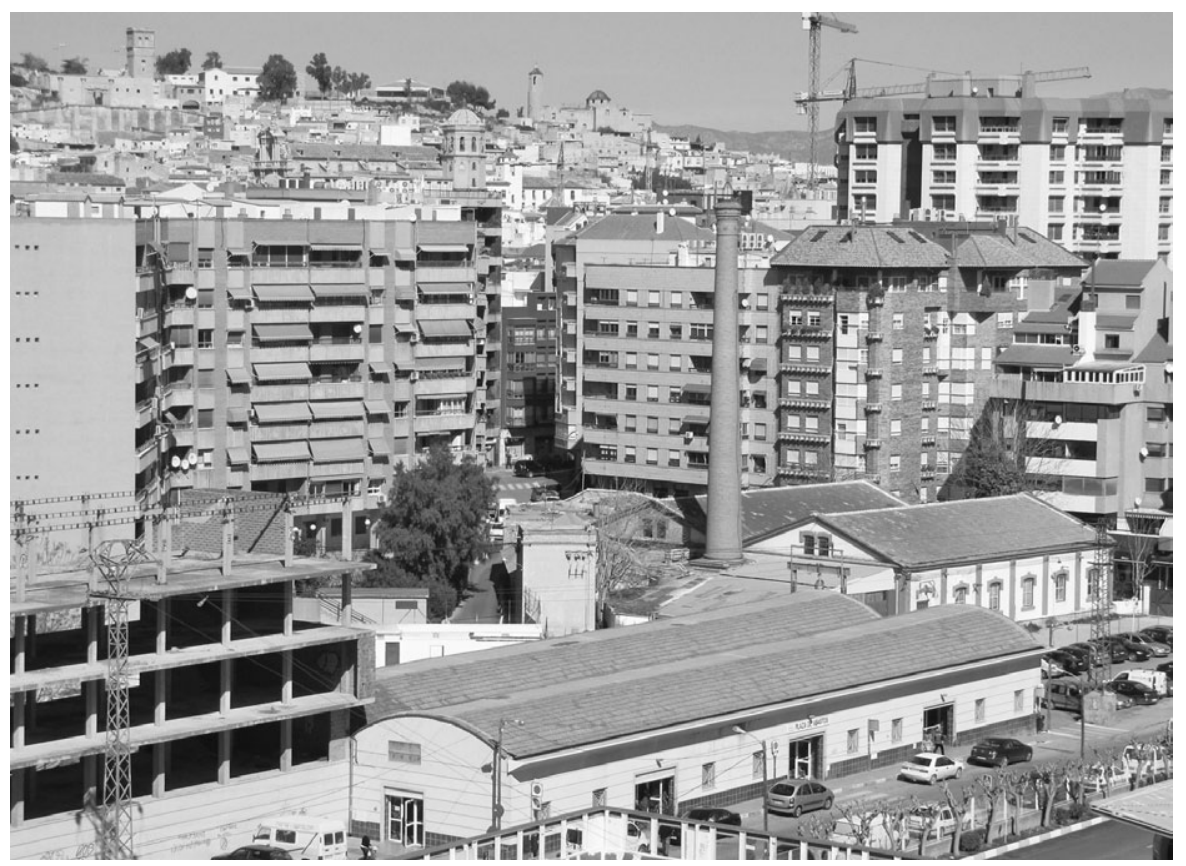

Fuente: Foto del autor.

zona verde y deportiva de la ciudad para recreo de su abundante población obrera (Romera, 2010).

No será hasta 1967 cuando se apruebe el PGOU de Lorca, incongruente en muchos aspectos y poco afortunado en cuanto a planteamientos y resultados prácticos. El plan proponía un modelo territorial centralizado en la capital donde se concentrara toda la actividad económica. Las zonas industriales las sitúa en los accesos desde Granada y Caravaca (34,6 ha. en total) y en polémicas zonas de tolerancia industrial (22,3 ha.) adosadas a áreas residenciales en San Diego y La Viña, las cuales fueron después reducidas por lógicas incompatibilidades. La falta de recursos económicos en el Ayuntamiento (el Estado llegó a aportar hasta el 30\% del presupuesto municipal) y de grandes inversiones privadas, obstaculizó la ejecución de las infraestructuras y servicios básicos que desarrollasen tales áreas productivas, lo que degeneró en el asentamiento espontáneo de las industrias. Romero e Ibáñez (1985) exponen bien esta problemática de entonces. En 1962 se pone en funcionamiento la 
Subestación Eléctrica de La Viña, garantizando el suministro a la población y a las industrias locales, alimentada por dos líneas de alta tensión de 132 y 66 kw. Hoy está en proceso de desmantelamiento por su traslado a la periferia y su transformación en una zona residencial de alta densidad.

La revisión de este plan se inició en 1978 aunque no llegará a aprobarse hasta 1987. Durante este periodo comienza la urbanización del polígono de Saprelorca, el primero de la comarca, en la carretera de Granada. En Plan de 1987 fue más realista con la situación de lento crecimiento poblacional del municipio, lo que quedó patente en la proyección urbanística de Lorca, la cual se hizo extensiva al resto del vasto término. Quedó claro en cuanto a localización industrial la especialización de la carretera de Caravaca en industria pesada sobre una superficie de 52,3 ha. y de industria ligera para la salida hacia Granada (13,2 ha.) más allá del barrio de San Antonio. No plantea solución alguna para la aglomeración industrial de Serrata, surgida en los años 60 por el desplazamiento de la industria química y del curtido desde la ciudad, quedando pendiente la resolución de cuantos costes ambientales y sociales lleva implícito.

El Plan actual, entrado en vigor en 2003, es mucho más ambicioso y contempla el aprovechamiento integral (quizá excesivo) de las potencialidades económicas de Lorca al ser redactado en una etapa de gran crecimiento, creando además una nueva estructura urbana para la ciudad lorquina. En cuanto a dotación industrial, el plan consolida las áreas ya existentes (Saprelorca, Los Peñones, La Hoya) contemplando futuras ampliaciones, la ordenación de Serrata con un nuevo parque empresarial, y la clasificación de suelo industrial en los núcleos rurales de población más importantes. El suelo urbanizable industrial-terciario previsto supera los 26 millones de metros cuadrados. Estos precedentes son estudiados con mayor detalle en Romera (2009).

\section{DOTACIÓN INDUSTRIAL Y ESPECIALIZACIÓN PRODUCTIVA}

Los últimos datos estadísticos ponen de manifiesto la existencia en Lorca de 7.108 empresas que suman 8.085 establecimientos y dan trabajo a casi 25.000 personas. De ellas, 549 se dedican a actividades industriales $(7,7 \%)$, totalizando 623 establecimientos y 3.325 trabajadores (13\% del total). A nivel regional, la industria lorquina vuelve a presentar resultados exiguos: $6 \%$ de las empresas y establecimientos fabriles y apenas el 4,3\% de los trabajadores, concentrados en el campo de Cartagena y en el área metropolitana de Murcia (CARM-Centro Regional de Estadística, 2010). La empresa industrial lorquina destaca por su pequeño tamaño: el $81 \%$ tiene menos de 5 empleados y el 16\% entre 5 y 50 . Sólo existen 9 empresas que cuentan con entre 51 y 99 
empleados y 5 con más de cien, todas ellas vinculadas a sectores significativos en el municipio: cementos y materiales de la construcción, curtidos, confección y alimentación. En 1982 estos mismos sectores resultaban ser también los más empleadores (Gris, 1985).

Como se aprecia en el Cuadro 3, más del 90\% de los industriales de Lorca trabaja en empresas manufactureras, destacando sobremanera los sectores de alimentación, bebidas y tabaco (cárnicas, embutidos, agroalimentarias); cuero y calzado (curtidos y marroquinería); metalurgia y fabricación de productos metálicos; transformación de caucho y materias plásticas (plástico para embalar productos alimenticios, para uso agrícola y ganadero); y el textil y confección. Sólo los tres primeros grupos dan empleo al 55\% del total. Igualmente, es de resaltar el crecimiento de las actividades relacionadas con la producción y distribución de energía (especialmente la solar), y las de gas y agua, las cuales, ya acogen al $8 \%$ de los activos dada la potencialidad del municipio.

Si se analizan los datos de inversión industrial en Lorca entre 1999 y 2005 se obtiene un pobre resultado global de 67,3 millones de euros (60\% para nueva industria), cifra que supone un tétrico 3,2\% de la inversión a nivel regional (2.113,5 millones), lo que vuelve a poner de manifiesto la escasa relevancia del sector en la ciudad, la falta de dinámica empresarial y de potenciación por parte de las diferentes administraciones a pesar de los recursos y oportunidades que el municipio ofrece. La inversión industrial se concentra en un $80 \%$ en el eje Murcia-Cartagena.

Cuadro 3: Empresas y establecimientos industriales según actividad en Lorca (2008)

\begin{tabular}{|l|r|r|r|r|r|r|}
\hline \multirow{2}{*}{ Actividad industrial } & \multicolumn{2}{|c|}{ Empresas } & \multicolumn{2}{c|}{ Establecimientos } & \multicolumn{2}{c|}{ Empleos } \\
\cline { 2 - 7 } & Núm. & $\%\left(^{*}\right)$ & Núm. & $\%\left({ }^{*}\right)$ & Núm. & $\%\left(^{*}\right)$ \\
\hline C. Extractivas & 8 & 1,45 & 14 & 2,25 & 111 & 3,43 \\
\hline D. Manufactureras & 431 & 78,51 & 494 & 79,29 & 3.009 & 93,01 \\
\hline $\begin{array}{l}\text { DA. Alimentación, bebidas y } \\
\text { tabaco }\end{array}$ & 94 & 17,12 & 114 & 18,30 & 926 & 28,62 \\
\hline DB. Textil y confección & 65 & 11,83 & 71 & 11,40 & 242 & 7,48 \\
\hline DC. Cuero y calzado & 32 & 5,83 & 36 & 5,78 & 492 & 15,21 \\
\hline DD. Madera y corcho & 22 & 4,01 & 25 & 4,01 & 82 & 2,53 \\
\hline DE. Papel, edición y artes gráficas & 21 & 3,83 & 24 & 3,85 & 86 & 2,66 \\
\hline DG. Química & 4 & 0,73 & 5 & 0,8 & 5 & 0,15 \\
\hline $\begin{array}{l}\text { DH. Transformación de caucho y } \\
\text { materias plásticas }\end{array}$ & 7 & 1,27 & 11 & 1,76 & 268 & 8,28 \\
\hline
\end{tabular}




\begin{tabular}{|l|r|r|r|r|r|r|}
\hline $\begin{array}{l}\text { DI. Otros productos minerales no } \\
\text { metálicos }\end{array}$ & 40 & 7,28 & 52 & 8,34 & 306 & 9,46 \\
\hline $\begin{array}{l}\text { DJ. Metalurgia y fabricación de } \\
\text { productos metálicos }\end{array}$ & 84 & 15,3 & 86 & 13,8 & 354 & 10,94 \\
\hline $\begin{array}{l}\text { DK. Construcción de maquinaria } \\
\text { y equipo mecánico }\end{array}$ & 20 & 3,64 & 21 & 3,37 & 127 & 3,92 \\
\hline $\begin{array}{l}\text { DL. Material y equipo eléctrico, } \\
\text { electrónico y óptico }\end{array}$ & 10 & 1,82 & 11 & 1,76 & 32 & 0,99 \\
\hline DM. Material de transporte & 5 & 0,91 & 6 & 0,96 & 20 & 0,62 \\
\hline DN. Manufactureras diversas & 27 & 4,92 & 32 & 5,14 & 69 & 2,13 \\
\hline $\begin{array}{l}\text { E. Producción y distribución de } \\
\text { energía, gas y agua }\end{array}$ & 110 & 20,03 & 115 & 18,46 & 254 & 7,85 \\
\hline TOTAL INDUSTRIA LORCA & 549 & 100,0 & 623 & 100,0 & 3.235 & 100,0 \\
\hline REGIÓN DE MURCIA & 9.258 & - & 10.401 & - & 74.093 & - \\
\hline \% LORCA / REGIÓN & 5,93 & - & 5,99 & - & 4,36 & - \\
\hline
\end{tabular}

Fuente: Centro Regional de Estadística (2008). (*): Porcentajes referidos al total.

Todas estas empresas y sus respectivos establecimientos industriales, se distribuyen en el extenso municipio lorquino siguiendo un esquema que parte de la trama urbana de la ciudad de Lorca y se prolonga a través de varias aglomeraciones industriales desordenadas hasta los polígonos industriales de la periferia, para finalizar con la industria dispersa por el espacio rural. En la actualidad, el suelo industrial urbanizado (polígonos industriales) en Lorca asciende a una superficie de 2.571.243 $\mathrm{m}^{2}$ (257 ha.), esto es, el 8\% del total regional $\left(31,7\right.$ millones de $\mathrm{m}^{2}$ ). Si añadimos el suelo ocupado por la aglomeración de Serrata, la cifra se sitúa en los $4.512 .791 \mathrm{~m}^{2}$.

\section{DISTRIBUCIÓN TERRITORIAL DE LA INDUSTRIA EN LORCA}

La disposición de las zonas industriales en Lorca, para la búsqueda de economías externas y de aglomeración (Figura 2), está fuertemente condicionada por el emplazamiento de la ciudad entre el contrafuerte de la sierra de la Peñarrubia y el valle del Guadalentín, y el trazado de las principales vías de comunicación, especialmente la A-7 (Autovía del Mediterráneo) y la antigua carretera nacional 340; ambas discurren por el municipio en sentido SO-NE. La otra vía primaria, transversal a las anteriores, es la RM-11 (Autovía LorcaÁguilas) y la RM-711 que comunica Lorca con Caravaca y Madrid y que será transformada también en autovía. Los puertos comerciales más cercanos son: Cartagena (90 km.), Alicante (143) y Almería (154). Próximos a ellos se encuentran importantes aeropuertos. El ferrocarril, aún sin modernizar, sólo 
Figura 2: Localización de las zonas industriales de Lorca

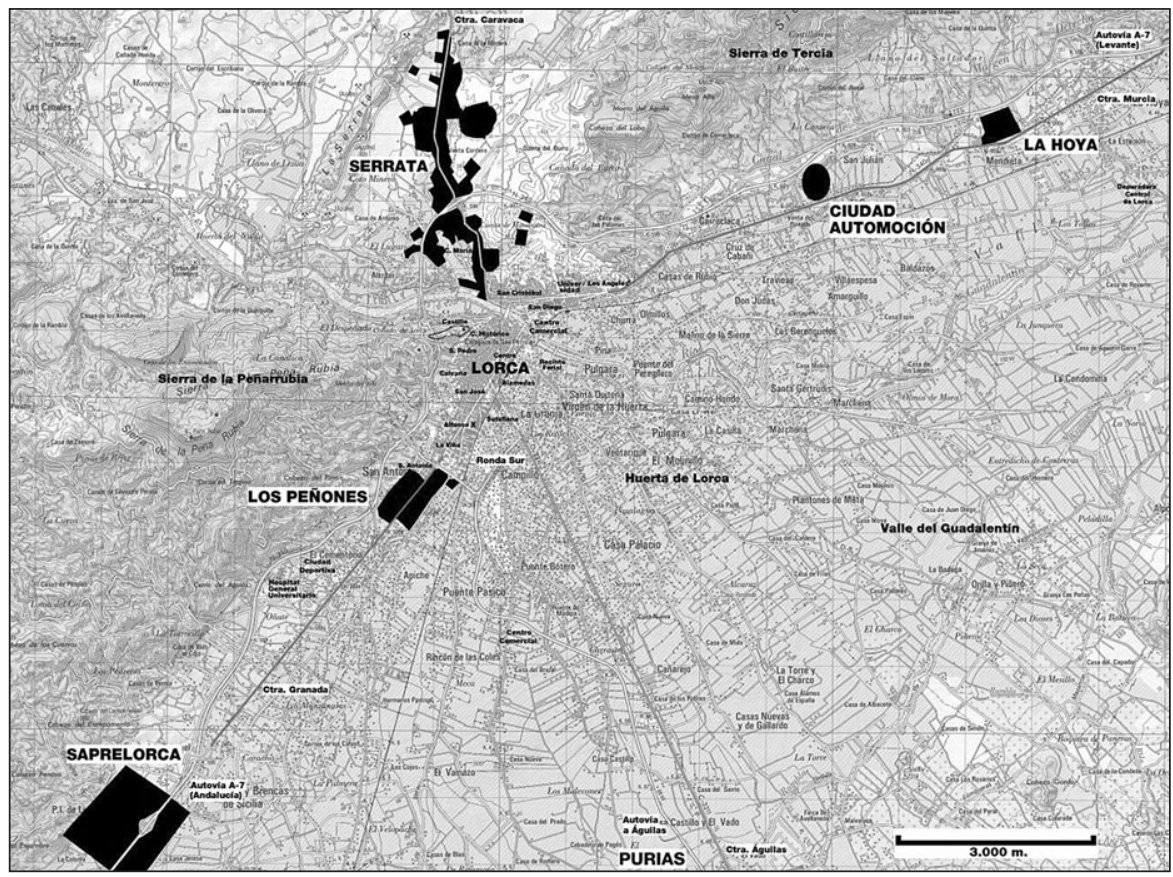

Fuente: Instituto Geográfico Nacional. MTN 1:50.000 (Hojas 953 y 975). Adaptación.

presta servicio para viajeros; el tráfico de mercancías fue reduciéndose hasta desaparecer a raíz del cierre de la línea Lorca-Granada en 1984. La llegada de la Alta Velocidad y la construcción de una gran terminal logística en el polígono de Saprelorca puede relanzar las posibilidades de este medio de transporte como una nueva oportunidad para la modernización de Lorca, como ha ocurrido en otras ciudades medias (Ganau y Vilagrasa, 2003). La Figura 3 refleja la densidad de tráfico en las carreteras que vertebran la aglomeración urbana de Lorca en relación directa con la ubicación de las zonas industriales. El traslado a la periferia de la industria lorquina ha modificado la movilidad interna de los trabajadores, forzando los movimientos pendulares entre las áreas residenciales centrales y periféricas y las áreas de producción, lo que da lugar a importantes problemas de tráfico en una ciudad de desarrollo lineal que centraliza las principales vías de comunicación de la comarca con escasos ejes transversales.

Existen multitud de teorías sobre la localización industrial (Méndez, 1995) que ponen de manifiesto la reciprocidad existente entre el espacio y la 
Figura 3: Aforos de tráfico en los accesos a Lorca y situación de las zonas industriales

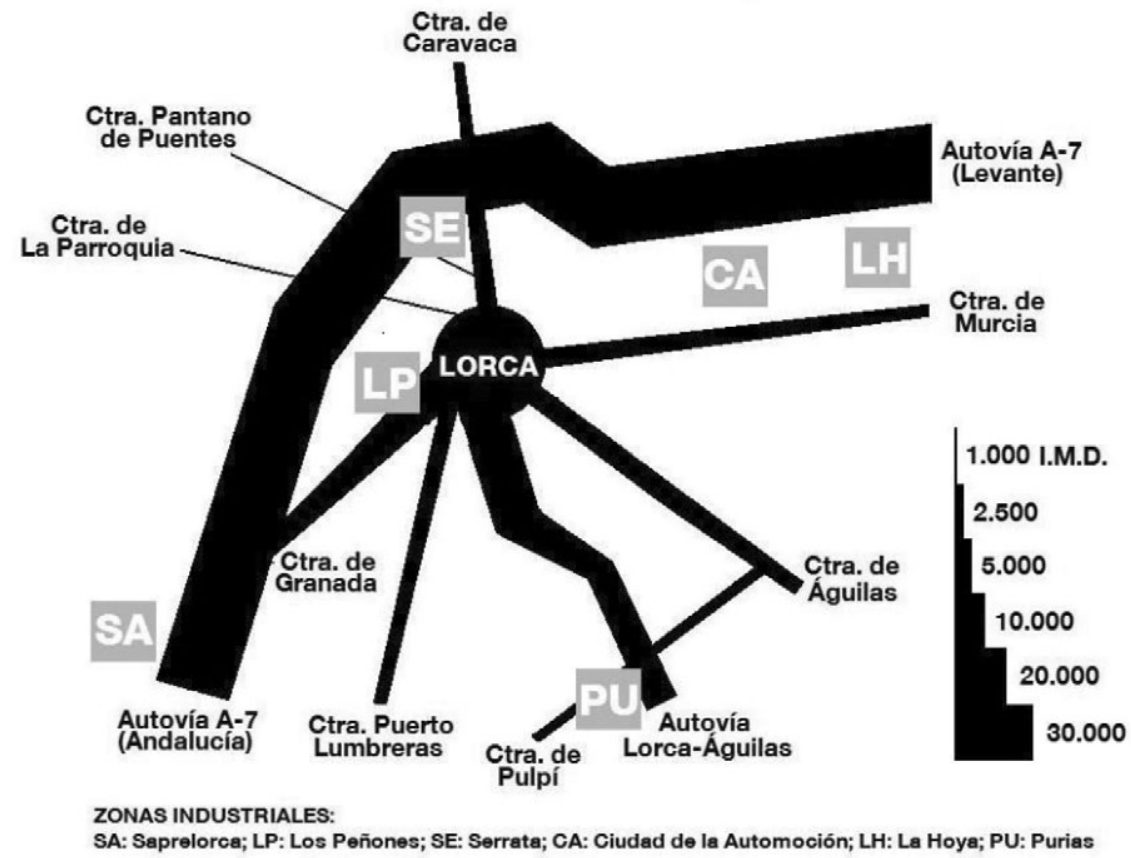

Fuente: CARM-Dirección General de Carreteras y Ministerio de Fomento. Intensidad Media Diaria de vehículos (IMD). Elaboración propia.

industria, incidiendo en la toma de decisiones empresariales sobre dónde ubicar una industria. Las pautas de localización suelen ser repetitivas y muestran preferencias espaciales que hacen concentrar la actividad empresarial en unas zonas en detrimento de otras a cualquier escala, en función de las utilidades y desutilidades (reales o percibidas) que ofrecen.

\subsection{Trama urbana de la ciudad. Desmantelamiento y sustitución}

La industria que queda en el interior del casco urbano de Lorca es muy reducida, al irse desplazando progresivamente a las afueras de la ciudad por necesidad de ampliación, mejora en la accesibilidad, por cuestiones de seguridad, emisión de residuos o de convivencia vecinal. Se puede afirmar que hoy no queda en la trama urbana ningún establecimiento industrial que cuente con más de ocho o diez trabajadores. Por lo general, tampoco suelen sobrepasar 
los $400 \mathrm{~m}^{2}$ de superficie y la potencia instalada es muy baja. Por otro lado, la presión urbanística de los últimos años ha cambiado el uso del suelo en algunos barrios periféricos que han visto crecer nuevos edificios y zonas comerciales en sustitución de viejas factorías. A pesar de ello, todavía quedan en Lorca algunas zonas que rezuman ambiente industrial y cuya principal consecuencia es el degradado paisaje urbano que ocasionan cuando las industrias dejan de estar en activo y quedan abandonadas (Romera, 2002).

Un buen ejemplo de emigración industrial a la periferia es la industria del curtido. El traslado de estas fábricas del barrio de San Cristóbal a la zona industrial de Serrata está motivado fundamentalmente por una etapa de expansión en el sector que impulsó la necesidad de contar con establecimientos de mayores dimensiones y medios técnicos más modernos en la década de 1970 (Segura e Ibáñez, 1990). Valga un ejemplo: la factoría que tenía Gabino García Serrano en 1972 en el camino de San Diego contaba con una potencia instalada de 354 kw. y 33 trabajadores; treinta y cinco años después, la nueva fábrica de Serrata contaba con una potencia de $1.283 \mathrm{kw}$. y una plantilla de 51 empleados. No obstante, las fábricas de curtidos en San Cristóbal en los años 60 tenían las dimensiones y capacidad que permitían los edificios urbanos destinados a tal fin. Así, la empresa «Viuda de Fulgencio Pelegrín Serrano» sólo tenía $64 \mathrm{kw}$. de potencia instalada y 14 obreros.

El profesor Gil (1968) resalta el ambiente ajetreado de los obreros de San Cristóbal en contraste con los empleados en el centro urbano, que salían de la fábrica o de la zona minera próxima casi exclusivamente para «despachar asuntos imprescindibles», remarcando que el paisaje urbano de aquella barriada estaba presidido en muchos lugares por el volumen y traza de las fábricas, cuya ubicación «no respeta ni los puntos más céntricos». Hasta la modernización del sector, este barrio ofrecía un «colorido y tufillo especial» en sus calles ante el rudimentario procedimiento de secado de las pieles tendidas en plena calle en grandes tablas. Idéntico camino llevaron otras empresas ubicadas en San Cristóbal, reseñadas por Sastre (2006): almazaras, fábricas de calzado, de caramelos, de chocolates, de harinas, cerámicas, alfarerías... de las que hoy no queda rastro (Figura 4). Antiguas fábricas de curtidos en San Ginés, al otro lado del río, fueron demolidas y los restos arqueológicos encontrados se están poniendo en valor al tiempo que el inmediato Convento de la Merced se ha convertido en un Centro de Recepción para Visitantes.

Algo parecido ocurrió ya en los años 90 y principios del nuevo milenio en el barrio de San José con antiguas fábricas cárnicas, de alimentación y alimentación animal. Tal fue el caso de «Cárnicas del Sureste» (40 empleados y $4.000 \mathrm{~m}^{2}$ ) que tuvo que ser trasladada a Saprelorca en 1997 por las 
Figura 4: Dotación industrial en el barrio de San Cristóbal de Lorca en 1950

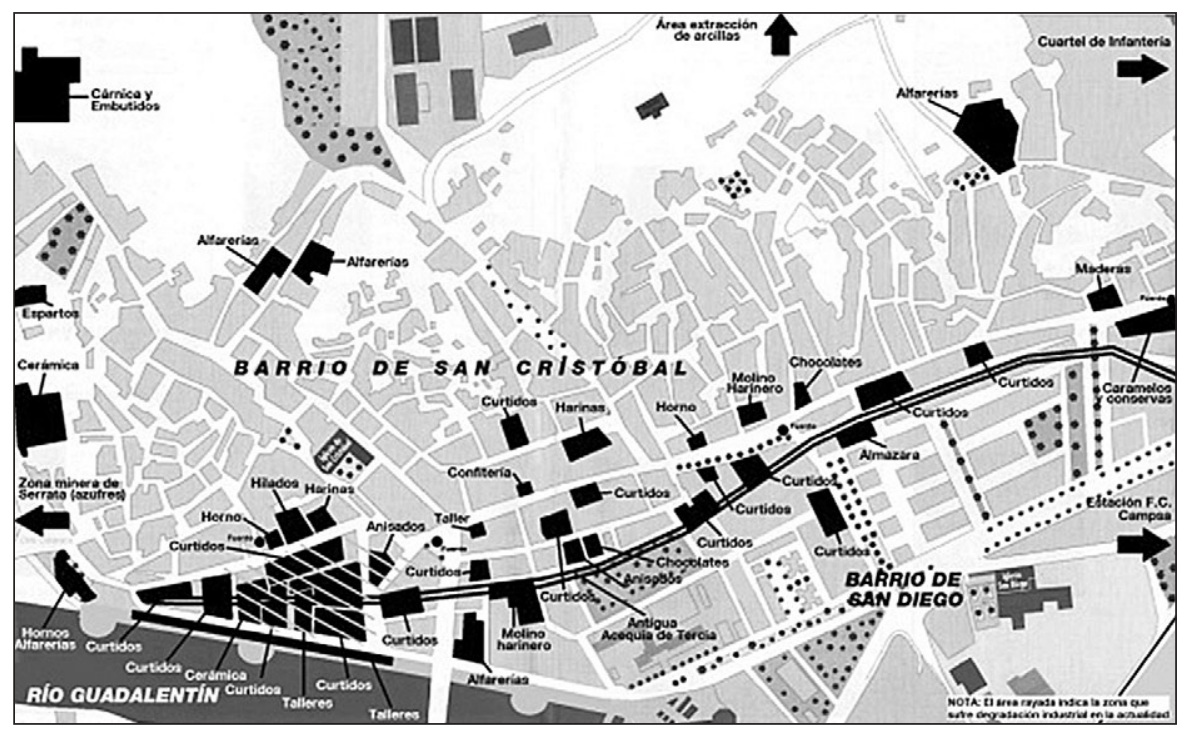

Fuente: Guirao (1949), folletos y cartografía de la época. Elaboración propia.

continuas molestias ocasionadas a los vecinos de la zona; hoy su solar se ha convertido en una urbanización privada. En el barrio de La Viña, a partir de 1975, desaparecen o se trasladan varias empresas del sector de la construcción (cerámicas), textiles, de la confección, y de la automoción (concesionarios, recambios, talleres...), siendo utilizadas las nuevas áreas que quedaron obsoletas para la construcción de nuevos bloques de pisos o su reconversión en centros comerciales especializados. En el centro de la ciudad toda reliquia industrial ha sido objeto de derribo, destacando la desaparición de la célebre fábrica de confección de «Bertrand» (levantada junto al palacio del Huerto Ruano en 1942, 250 obreros), modelo arquitectónico para otras muchas, en 1979, por su traslado a la carretera de Puerto Lumbreras y su sustitución por un residencial de 132 pisos; o las fábricas de ladrillo y cerámicas (llegaron a existir hasta nueve) que han sido pasto de la urbanización masiva, de la que se han librado dos altivas chimeneas. Hasta hace poco tiempo se han reutilizado las naves de la antigua Fábrica de la Luz para oficinas municipales; pronto serán demolidas para construir allí la torre de viviendas más alta de Lorca (16 plantas) y una plaza de $6.600 \mathrm{~m}^{2}$.

Como es de esperar, en el casco urbano sólo destaca la presencia de pequeños establecimientos industriales dedicados al sector de la alimentación 
(embutidos, panificadoras, hornos, elaboración de helados, aceites, confiterías...), pequeños talleres mecánicos, de chapa y pintura, o dedicados a la confección; carpinterías, muebles, tapicerías o imprentas. La distribución de estos establecimientos está muy dispersa, aunque destaca la dotación de los barrios periféricos de Los Ángeles y Apolonia (automoción y muebles), San Cristóbal (talleres diversos, materiales de la construcción, plantas aromáticas, productos artesanos), La Viña (automoción, textiles), Santa Quiteria y Virgen de las Huertas. En estos últimos existe una cierta especialización con el sector agropecuario al quedar inmediatos a la huerta lorquina.

Los espacios más afectados por la actividad industrial en el medio urbano se sitúan en los distritos de San Cristóbal y La Viña. En La Viña todavía ocupan el 20\% del espacio edificado las naves industriales, algunas clausuradas a la espera de una recalificación y otras en activo. En San Cristóbal, a pesar de la intensa renovación urbana de los últimos diez años, todavía queda una manzana de grandes dimensiones con naves abandonadas entre las calles Eulogio Periago y San Fernando; en ese espacio se tramita un ARI (Área de Rehabilitación Interior) que va a regenerar toda la zona.

\subsection{Aglomeración industrial de Serrata}

Ya fuera del perímetro urbano aparece la zona industrial de Serrata, localizada al norte de la ciudad siguiendo el eje de la carretera de Caravaca. Se trata de una aglomeración industrial muy característica (Gómez, 1984) al reunir todas las cualidades que presentan las zonas industriales desordenadas: ausencia de planeamiento previo, ha sido promovido por la iniciativa privada, asentamiento al libre albedrío de las fábricas, falta de servicios de urbanización básicos, bajo precio del suelo, alineación de las industrias siguiendo los ejes de comunicación, mezcolanza en los usos del suelo, incompatibilidad con zonas residenciales y problemas ambientales diversos. La falta de espacios industriales planificados por la administración dejó sin opción a los empresarios lorquinos que tuvieron que ampliar sus instalaciones fuera del espacio urbano allí donde era posible (Figura 5).

Las primeras industrias que se instalaron en Serrata en la segunda mitad de los años 60 fueron las de curtidos. No fue por casualidad. Esta actividad se venía asentando desde el siglo XVIII en el industrioso barrio de San Cristóbal, muy próximo a Serrata, por tres razones fundamentales: la existencia de mano de obra abundante y especializada, la disponibilidad de agua potable (desde 1781) y el aprovechamiento del río Guadalentín para la captación de sus escasos caudales, la obtención de energía (acequias) y su utilización como colector residual junto a la antigua acequia de Tercia. La necesidad de ampliación 
Figura 5: Aglomeración industrial de Serrata (vista parcial)

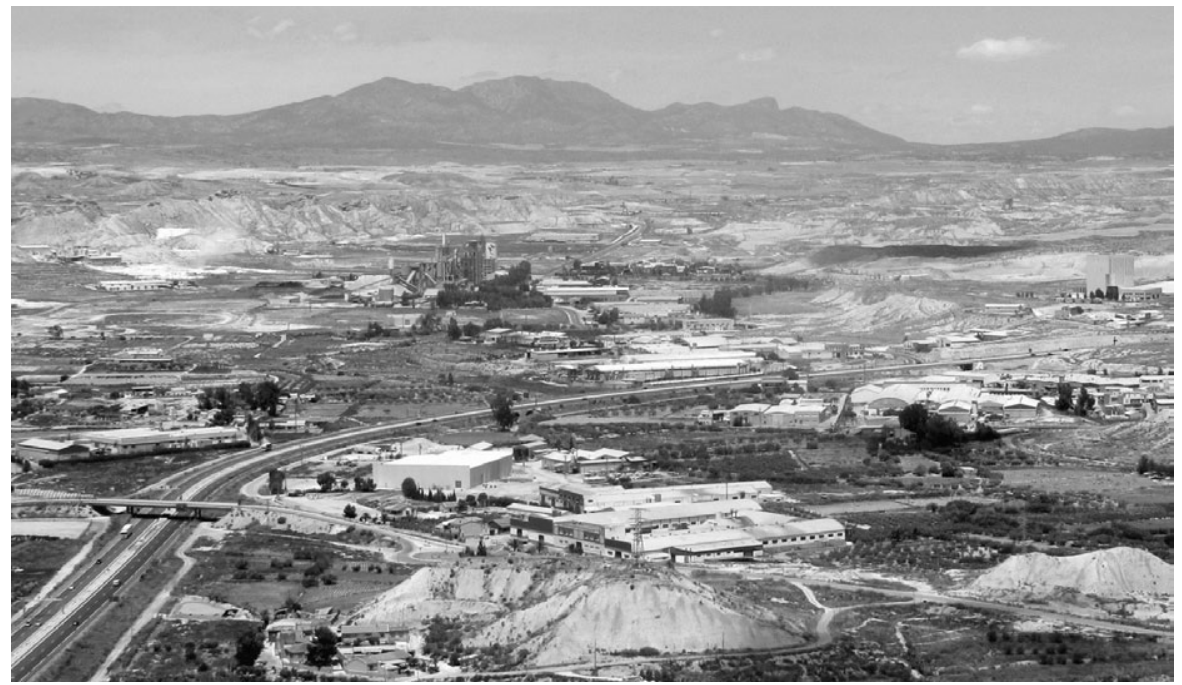

Fuente: Foto del autor.

de las fábricas y la riada de 1973 favoreció el traslado de las mismas a un lugar cercano en la periferia. No quedó otra opción que Serrata por proximidad, bajo precio del suelo, buen acceso y su nulo aprovechamiento agrario al predominar los materiales margosos (bad-lands). En Plan General de 1987 clasificó esta aglomeración como suelo no urbanizable, pero estableció una confusa delimitación de «tolerancia especial» para las industrias del curtido.

El espaldarazo definitivo de Serrata como enclave industrial se produjo con la puesta en funcionamiento de la multinacional «Holcim» en julio de 1967 con una producción inicial de 400.000 toneladas anuales de cemento y clinker (en 2007 se supera el millón de toneladas y cuenta con una plantilla de 800 personas). Paulatinamente se fueron asentando otras industrias auxiliares al curtido (químicas, fabricación de bombos, transportes) aunque no se consiguió el cierre del ciclo productivo con el desarrollo de una industria del calzado o marroquinería que hubiera resultado muy rentable; se optó por enviar la producción semielaborada, principalmente, al valle del Vinalopó (Alicante). También cuenta con un peso destacable la industria cárnica, hallándose aquí la más grande de la ciudad (200 trabajadores) y la más antigua (de 1929), propiedad ahora de la mayor cooperativa de la Región, «Alimer», que cuenta con 1.540 socios; junto a ella, se localiza el Matadero Comarcal (1988) que pronto será sustituido por otro más moderno y funcional previa 
recalificación de los terrenos actuales, en los que se permitirá la construcción de un residencial de 1.500 viviendas según el convenio urbanístico. En Serrata también están radicadas buen número de empresas ligadas a la extracción de áridos (canteras), materiales para la construcción, fertilizantes, productos metálicos, cerrajerías, carpinterías, talleres mecánicos y algunas empresas de servicios. El conjunto de estas empresas llegó a suponer el 44\% de la producción industrial local (Cámara de Comercio, 1991).

Esta aglomeración industrial ocupa una extensión en cuanto a parcelas industriales de 196,5 ha. $\left(1.965 .700 \mathrm{~m}^{2}\right)$, aunque si se tienen en cuenta las zonas intersticiales podría superar las 300 ha. Está estructurada en torno a un eje de comunicación primario, la carretera de Caravaca, que atraviesa de $\mathrm{N}$ a $\mathrm{S}$ este complejo en 4,2 km. Por otro lado, fraccionan este espacio la autovía A-7 (en sentido transversal), dotando a Serrata de gran accesibilidad, la carretera secundaria que se dirige al pantano de Puentes y la rambla Salada que hace de este ámbito un lugar vulnerable en caso de lluvias de gran intensidad. Algunas zonas de huerta en minifundio con poblamiento disperso en las proximidades de la ribera del Guadalentín, la existencia de núcleos de población periféricos, el aprovechamiento que se realiza de algunas canteras a cielo abierto, el trasiego continuo de vehículos de gran tonelaje y la presencia de contaminantes (aguas residuales del curtido, líneas de alta tensión, tráfico rodado, residuos sólidos y gaseosos), completan un complejo panorama de difícil remedio.

La solución al problema de las aguas residuales del curtido (con alto contenido en cromo y sulfuros) ha sido fallida durante mucho tiempo. En 1988 se inauguraba por iniciativa de los propios industriales, tras veinte años de vertidos al Guadalentín, una depuradora con sistema de lagunaje con capacidad para depurar $3.500 \mathrm{~m}^{3} /$ día de aguas residuales que resultó un fiasco por problemas en el proceso y la emanación de ácido sulfídrico en una zona densamente poblada; en 1993 la Justicia ordenó su cierre definitivo por afecciones en algunos vecinos y las aguas volvieron al río. En 2000 se ponía en marcha una nueva depuradora capaz de depurar $12.000 \mathrm{~m}^{3}$ de aguas residuales al día en un momento en el que el sector se encontraba en plena ebullición: 25 empresas, empleo directo e indirecto superior a las 2.000 personas, una facturación anual de 150 millones de euros y un peso específico del $12 \%$ a nivel nacional. Todo ello contrasta con la languidez actual tras el cierre de muchas empresas y la pérdida de cientos de puestos de trabajo por la crisis financiera y la deslocalización empresarial al Norte de África y Sudeste asiático. En 2008, antes de la crisis actual, se hallaban censadas en el Registro de Actividades Industriales de la Comunidad Autónoma 23 fábricas de curtidos con una potencia instalada de 20.464 kw. y 783 empleos directos. 
El futuro de esta aglomeración industrial está en el desarrollo del Parque Empresarial Serrata, previsto en el actual PGOU con una reserva de suelo de 12 millones de $\mathrm{m}^{2}$ (la mayor de la Región), dividido en seis sectores, de los que tres (el 2, 5 y 6) se encuentran en proceso de tramitación, con la participación de entidades públicas y privadas. El más avanzado de todos es el sector 2-I, cuyo proyecto fue redactado en 2005 con objeto de atraer empresas foráneas. Ocupa una extensión de 1,24 millones de $\mathrm{m}^{2}$ y posibilitará la creación de 350 parcelas para industrias de gran tamaño (más de $20.000 \mathrm{~m}^{2}$ ) y un gran centro comercial y de negocios. Aquí se pretende instalar el futuro Matadero Regional (400 empleos) y un centro logístico-puente, teniendo en cuenta que la transformación en autovía de la carretera de Caravaca permitirá la conexión directa entre Andalucía, Albacete y Madrid a través de Lorca evitando así el saturado nudo de Murcia. Por otro lado, el PGOU vigente, clasifica como suelo residencial urbanizable todo el espacio de Serrata comprendido entre la autovía A-7 y el río Guadalentín como zona de expansión del barrio de San Cristóbal, obligando a medio plazo a las empresas industriales aquí asentadas, a ser trasladadas, una vez más, al nuevo parque empresarial.

\subsection{Polígono industrial de Los Peñones}

A mediados de la década de 1960, la carretera de Granada se convierte en un eje preferente en torno al cual se van a ir instalando empresas de ramas diversas. Se trata de una carretera nacional muy transitada, de acceso obligado para clientes potenciales de la comarca natural de Lorca, el precio del terreno es bajo, se dispone de los servicios urbanos básicos y la debilidad topográfica favorece la implantación de las industrias en aquel momento, ya fuesen de nueva creación o la ampliación de otras en el extrarradio.

Como ya se indicó, el Plan General de 1952 ya planeaba aquí un importante asentamiento fabril, ratificado como zona de tolerancia industrial en el de 1967. A pesar de la apertura progresiva de nuevas fábricas, la urbanización de este espacio no se llevó a cabo como tampoco el desarrollo de unidades de actuación que ordenaran la zona por falta de recursos municipales. Comenzaba a fraguarse, por iniciativa privada y de forma desordenada, la aglomeración industrial de Los Peñones.

Con el PGOU de 1987 se pretende ordenar y urbanizar toda la zona por medio de dos unidades de actuación. Se trazan sobre el papel, según la disposición de las fábricas, las nuevas calles, equipamientos y servicios básicos que pretenden convertir la aglomeración en un polígono industrial; alguna de esas empresas quedó fuera de ordenación. Con el Plan de 2003, este polígono queda integrado en el casco urbano de Lorca con la calificación de suelo urbano y 
prevé su expansión a corto plazo hacia el oeste. Tras una larga tramitación administrativa de más de diez años, en 2008 finalizan las obras de urbanización y acondicionamiento del polígono, incluyendo la reparcelación de $82.200 \mathrm{~m}^{2}$ (21 nuevas parcelas), la construcción de un nuevo colector general, redes de saneamiento y agua potable; su coste superó los 500.000 euros.

Ahora el polígono de Los Peñones presenta una superficie de $535.848 \mathrm{~m}^{2}$ distribuidos entre un centenar de establecimientos industriales con parcelas que van de 1.000 a $20.000 \mathrm{~m}^{2}$; casi todas tienen un perímetro longitudinal en fondo de saco. El frente urbanizado en ambas márgenes de la carretera de Granada es de 1.050 metros (Figura 6). A excepción de los viales y una pequeña zona deportiva $\left(7.300 \mathrm{~m}^{2}\right)$, el resto del espacio está ocupado por las instalaciones industriales, ocupadas y edificadas en un $85 \%$. Se prevé a corto plazo la ampliación del complejo en $100.000 \mathrm{~m}^{2}$ hasta alcanzar otro enlace de la A-7. Los sectores representados aquí son muy variados, aunque se puede afirmar la existencia de cierta especialización en el sector de la automoción (concesionarios, talleres, recambios, rectificados, chapa y pintura, carrocerías, neumáticos...) con una veintena de empresas. Destacan además los sectores:

Figura 6: Especialización industrial del polígono de Los Peñones

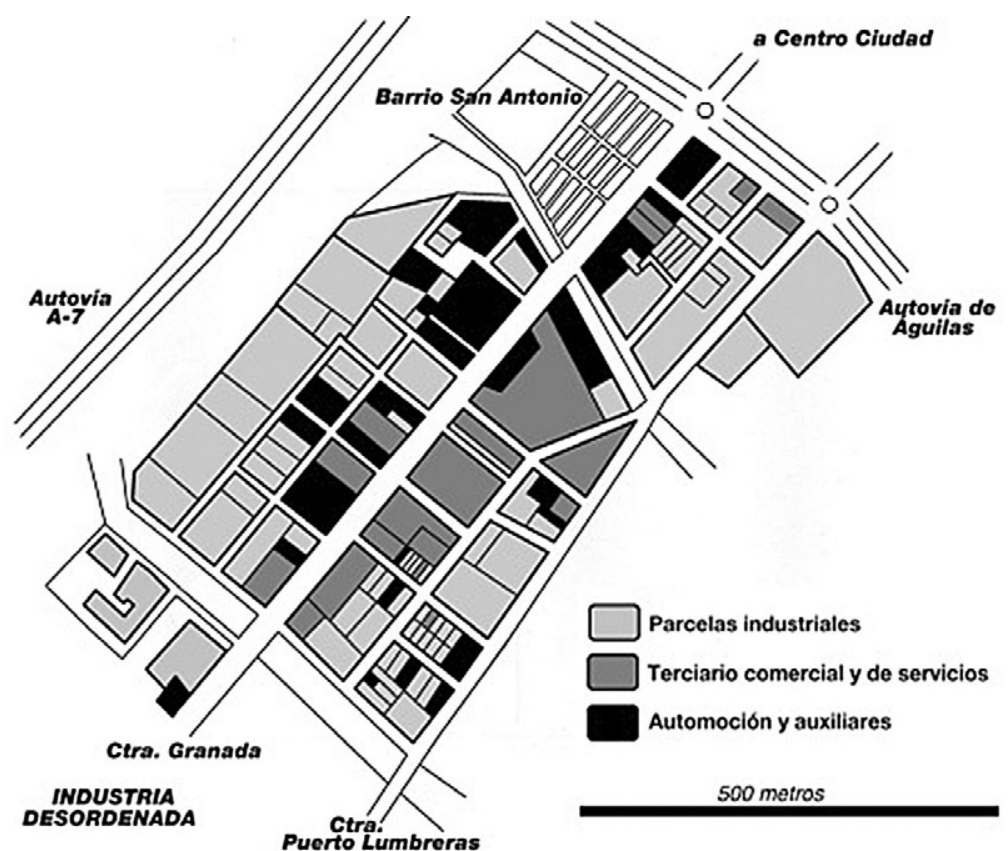

Fuente: Trabajo de campo. 
alimentación (pastas, frutas), materiales de la construcción (piedra artificial, aglomerados, cerámica), alimentación animal (piensos compuestos), textil y confección, maquinaria diversa, productos metálicos y fabricación de muebles.

El alto grado de ocupación de Los Peñones está muy ligado a su emplazamiento estratégico en una de las principales salidas de la ciudad al quedar directamente conectado con las autovías A-7, de Águilas, la Ronda Sur y el centro urbano. Por esto, a las empresas industriales ya mencionadas, se añaden otras de servicios personales o a las empresas necesitadas de escaparate, hoteles, restaurantes de comida rápida, centros comerciales especializados (muebles, hogar, electrodomésticos, juguetes...) que aprovechan las oportunidades que ofrece una vía por la que transitan diariamente 20.000 vehículos. Aquí tiene su sede el Parque de Bomberos y muy próximo el Centro Integral de Seguridad. Los costes ambientales y sociales que genera este enclave industrial y terciario son sufridos directamente por los vecinos del barrio de San Antonio.

\subsection{Parque Empresarial Saprelorca}

La mayor zona industrial de Lorca es el polígono de Saprelorca, ubicado a $6 \mathrm{~km}$. al oeste de la ciudad y atravesado por la A-7 en dirección a Granada. Cuenta con una superficie próxima a los dos millones de $\mathrm{m}^{2}$ tras las últimas ampliaciones, siendo uno de los mayores de la Región de Murcia y también de los primeros en ponerse en activo. La grave situación en que se encontraba la economía lorquina en la década de 1970, con la consecuente emigración (17.500 personas marcharon de Lorca en los años 60), propició la realización de un estudio sobre la programación económica del municipio para el periodo 1973-1980 donde se puso de manifiesto la conveniente creación de dos polígonos industriales, la declaración de preferente localización industrial y la potenciación de sectores tradicionales en auge para aumentar la renta per cápita de la comarca, frenar la emigración y diversificar la economía local (Promeconsa, 1972).

En 1978 se iniciaron los contactos por parte de la Cámara de Comercio e Industria de Lorca con empresarios de la comarca para la puesta en marcha de un polígono industrial, quedando comprometidos con el proyecto, 78. Poco después se inician los trámites administrativos y en 1981 se consigue la declaración del polígono como de Preferente Localización Industrial tras 18 meses en los que el Ayuntamiento no concede licencia para nuevas industrias por falta de suelo y la consecuente fuga de empresas a otros municipios. De los ocho emplazamientos propuestos, la mayoría en la carretera de Granada y 
en Serrata-Barranco Hondo, se eligió el que mejores condiciones económicas, de accesibilidad y proximidad a la ciudad ofrecía. En 1982 se crea Saprelorca como entidad (de capital mixto) encargada de la promoción y mantenimiento del polígono, y se aprueba la modificación del PGOU. Al año siguiente se inician las obras de urbanización sobre una superficie de $750.000 \mathrm{~m}^{2}$ adquiridos a 0,32 euros $/ \mathrm{m}^{2}$, resultando 113 parcelas de entre 1.200 y $20.000 \mathrm{~m}^{2}$. El precio de venta fue de los más baratos del país: 7,21 euros $/ \mathrm{m}^{2}$. El capital social inicial de Saprelorca fue de 961.619 euros cuya distribución por entidades ha variado con el paso del tiempo: Comunidad Autónoma (en 1982, 12,5\%; ahora, $32,6 \%)$; Ayuntamiento (12,5\% y $15,8 \%$ respectivamente); el SEPES (31,3\% y 40,4\%); Cajas de Ahorros (6,2\% y 5\%); Cámara de Comercio e Industria ( $0,6 \%$ y $0,7 \%)$; empresarios ( $21,2 \%$ y $0,5 \%)$; y el IMPI ( $15,6 \%$ y $0 \%)$. La Preferente Localización Industrial (Real Decreto 1.415/1981 de 5 de junio) conllevó importantes ventajas para los empresarios que se instalaron en Saprelorca: reducción de hasta el 95\% en tasas fiscales, preferencia para la obtención de créditos y subvenciones de hasta el $20 \%$ en inversiones en capital fijo.

En 1985 las obras de urbanización finalizan. La superficie vendida crece con rapidez y el número de fábricas instaladas aumenta año tras año dadas las ventajas antes reseñadas, de tal suerte que en 1989 está vendido el 50\% de las parcelas y en 1993 se alcanzará el 80\%, lo que se tradujo en la necesaria ampliación del complejo en 1996 financiada por el SEPES: $165.250 \mathrm{~m}^{2}$ más distribuidos en 44 nuevas parcelas, vendidas íntegramente en 2002. Por estas fechas, se da luz verde a una segunda ampliación inaugurada en 2004, ahora al otro lado de la A-7, de $301.103 \mathrm{~m}^{2}$ y 62 parcelas, vendidas en apenas dos años, dada la fuerte demanda de suelo industrial. La tercera ampliación (2006) supone añadir al polígono una superficie de $359.890 \mathrm{~m}^{2}$ y 92 parcelas más. Ahora se acomete la cuarta ampliación de Saprelorca sobre un espacio de $260.000 \mathrm{~m}^{2}$ donde una multinacional turca construye su factoría y se tramitan varios planes parciales para incorporar al complejo 129 ha. de suelo industrial. Hasta el año 2008 la venta de parcelas había ascendido a 15 millones de euros y la inversión industrial se cuantificaba en 16,5 millones.

Ahora el polígono de Saprelorca tiene una extensión total de $1.571 .243 \mathrm{~m}^{2}$ ( $1.831 .243 \mathrm{~m}^{2}$ con la ampliación en curso), 312 parcelas (casi todas vendidas y un $75 \%$ edificadas) y 203 empresas instaladas que dan empleo a más de 3.000 personas (Figura 7). De la superficie total, el 65\% se dedica a parcelas industriales, el $15 \%$ a viales, el $12 \%$ a zonas verdes y el $6 \%$ a zonas comerciales y equipamientos. Las normas urbanísticas especifican: altura máxima de las edificaciones de 8,5 metros, ocupación máxima del $80 \%$ y una edificabilidad tope de $0,90 \mathrm{~m}^{2} / \mathrm{m}^{2}$. Los servicios con los que cuenta este complejo industrial 
Figura 7: Parque empresarial Saprelorca

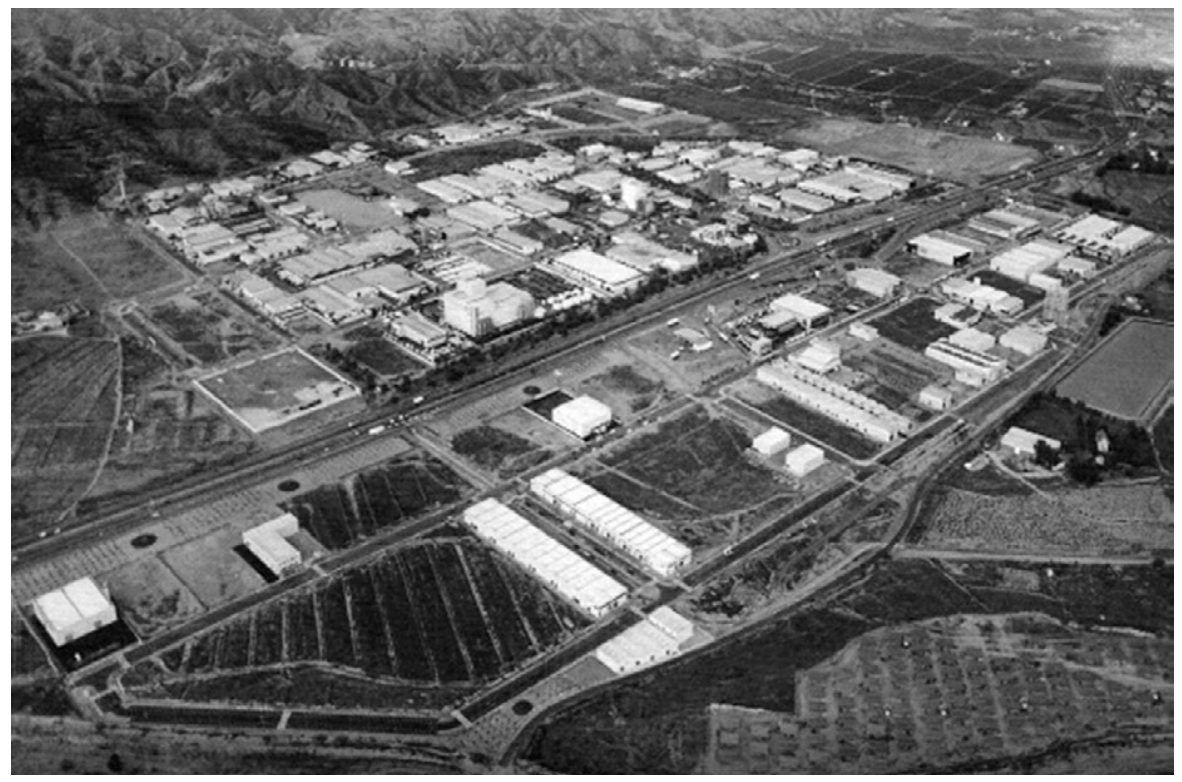

Fuente: Saprelorca (2007).

son los propios de una importante zona empresarial, incluyendo un Centro de Transportes.

Saprelorca, más que un polígono industrial, se ha convertido en un Parque Empresarial, dada la variedad de actividades que desempeñan las empresas implantadas. Según datos del Directorio Empresarial, Saprelorca puede quedar especializado en los sectores: comercial (distribución al por mayor y al por menor) con el 15\% de las empresas, $11 \%$ para las dedicadas al sector de la construcción (áridos, fontanería, productos metálicos, cerrajería, pintura...); servicios a otras empresas (lavanderías, almacenaje, seguridad, consultorías...) con el $10 \%$ del total; empresas ligadas a la automoción y al transporte (9\%); y la alimentación (9\%). También llama la atención el peso con el que cuentan las empresas de mobiliario urbano, publicidad y artes gráficas; fabricación o venta de maquinaria; sector eléctrico; cárnico y de embutidos; las ligadas al sector agrario; curtidos y textil; sector de la madera; y de materiales plásticos. Asimismo, encontramos varias torres de oficinas como nuevos centros de negocios dada la saturación del mercado de oficinas en la ciudad y un Laboratorio Tecnológico del Curtido, dependiente de la Comunidad Autónoma, infrautilizado y en fase de desmantelamiento. 
Según un estudio realizado por Saprelorca (2007), el 80\% de las empresas ubicadas aquí tiene un volumen de ingresos inferior a los tres millones de euros (445 millones en total); el 81\% de los trabajadores proceden de Lorca y un $14 \%$ de Puerto Lumbreras; la mitad de las materias primas y productos semielaborados proceden del resto de España, mientras que las ventas se dirigen al mercado local (18\%), regional (18\%), nacional (38\%) e internacional (16\%) en estas proporciones.

Por último, las empresas más importantes que se han instalado en este parque empresarial son: «Solplast» (1986), la mayor del polígono hasta ahora, dedicada al sector del plástico para la agricultura y derivados; su implantación sobre una parcela de $24.000 \mathrm{~m}^{2}$ supuso el lanzamiento empresarial de Saprelorca, dando empleo a 128 personas y cuyas ventas en el último ejercicio ascendieron a 58,7 millones de euros. La empresa italiana «Coopbox Hispania» (1994), dedicada a la fabricación de envases y embalajes para uso alimentario, sobre una parcela de $26.000 \mathrm{~m}^{2}$, una inversión inicial de 72,2 millones de euros (25\% subvencionado) y una plantilla de 120 personas, siendo la primera multinacional que se ubica aquí. Y la textil para señora "Confecciones San Francisco», creada en 1962, siendo la primera fábrica junto a «Piensos Frandi» que se instala en 1984 sobre una parcela de $15.000 \mathrm{~m}^{2}$; cuenta con una potencia instalada de $500 \mathrm{kw}$. y una plantilla de 75 personas. En estos momentos, se está ultimando la construcción de una factoría por parte de la multinacional turca «Noksel» sobre una parcela de $96.000 \mathrm{~m}^{2}$ destinada a la producción de tubos para la canalización de gas y petróleo, con una capacidad máxima de producción de 75.000 toneladas anuales y la generación de 220 puestos de trabajo directos y 700 indirectos; la inversión prevista supera los 30 millones de euros.

Como zona industrial complementaria a Saprelorca, se encuentra el Polígono Industrial de Puerto Lumbreras con una superficie de $224.700 \mathrm{~m}^{2}$ y 44 parcelas con un nivel de ocupación muy alto, estando prevista su próxima ampliación. Entre ambos, se pretende configurar la mayor aglomeración industrial y logística entre Murcia y Almería.

\subsection{Poligono industrial de La Hoya}

A 6,5 km. de Lorca, en dirección a Murcia, entre la A-7 y la antigua carretera nacional 340, se localiza el polígono de La Hoya, especializado en empresas del sector agropecuario al quedar inmediato a extensas áreas de producción agrícola y ganadera intensiva (frutas, hortalizas, ganadería porcina). Fue promovido por el Ayuntamiento de Lorca a través de SUVILOR (empresa municipal de suelo y vivienda). Su gestación se inició en 1998 cuando se detectó una 
alta demanda de suelo industrial en la zona, tratando de canalizar y ordenar futuros desarrollos y evitar así la dispersión y la generación de deseconomías. Las obras se inician en 1999 para quedar concluidas en julio de 2000 tras realizar una inversión de 2,7 millones de euros. La venta de parcelas fue muy rápida y a los pocos meses ya estaba vendido el $85 \%$ de la oferta a un precio medio muy competitivo: 22,2 euros $/ \mathrm{m}^{2}$.

La superficie del complejo es de $240.000 \mathrm{~m}^{2}$, de los que 184.047 están urbanizados. De éstos, el 76\% (141.555 $\left.\mathrm{m}^{2}\right)$ se destina a uso industrial, 20.502 $\mathrm{m}^{2}$ para zonas verdes, 13.890 para viales, 2.000 para zona comercial y 6.100 para equipamiento social y deportivo. El número de parcelas resultantes es de 67 , con tamaños comprendidos entre 682 y $17.467 \mathrm{~m}^{2}$. Cuenta con todos los servicios urbanos, quedando muy próxima la Depuradora Central de Lorca. En la actualidad, el 90\% de las parcelas está edificado y se está tramitando la ampliación del polígono en $100.000 \mathrm{~m}^{2}$ más ante el éxito obtenido.

Aprovechando esta nueva oferta de suelo industrial, en mayo de 2000 se inauguró la «Lonja de Lorca», un mercado para venta al por mayor de frutas y hortalizas con 26 puestos, que sustituyó a la anterior (de 1967) de acceso más problemático al quedar por el crecimiento urbano en medio de la ciudad. Las empresas ubicadas en el polígono de La Hoya se dedican a los sectores: agroalimentario, piensos y explotación de recursos ganaderos, cárnico y de embutidos, sector del transporte, materiales para la construcción y servicios personales y a las empresas. Entre las fábricas más destacadas, podemos citar la «SAT 2.439 TAS» (piensos compuestos, $1.348 \mathrm{kw}$. de potencia y $43 \mathrm{em}-$ pleados), y la «Cooperativa Sacoje», dedicada al sector hortofrutícola, con 52 empleados.

\subsection{Polígono Ciudad Regional de la Automoción}

Este polígono, de curiosa planta elipsoidal, es inédito en Europa. Se localiza a $3,5 \mathrm{~km}$. al este de la ciudad, entre la A-7 y la antigua carretera nacional. Cuenta con una superficie de $200.000 \mathrm{~m}^{2}$ y un total de 47 parcelas de entre 800 y $4.000 \mathrm{~m}^{2}$, estando vendido un $80 \%$. En ellas se están instalando concesionarios de automoción y empresas dedicadas a la venta de vehículos usados, talleres, recambios, accesorios y todo tipo de negocios relacionados con el sector. Las obras se iniciaron en julio de 2004 y se inauguraron en diciembre del año siguiente tras realizar una inversión de seis millones de euros. El proyecto está participado tanto por la iniciativa privada (VEHILOR, que agrupa a los marquistas de Lorca) como por la empresa municipal SUVILOR.

La distribución del área urbanizada es la siguiente: parcelas industriales $\left(118.713 \mathrm{~m}^{2}\right.$, el 60\%), zonas verdes y de ocio (20.000), equipamientos 
(10.000) y viales (49.558) entre otros. Las normas urbanísticas establecen una ocupación máxima del $90 \%$ de parcela, 16 metros de altura para las edificaciones y una edificabilidad media de $0,90 \mathrm{~m}^{2} / \mathrm{m}^{2}$. Según se vaya desarrollando el proyecto, se prevé la apertura nuevos servicios: hotel y restaurante, centro de ocio, servicios financieros y de gestión y un Parque Infantil de Tráfico y Educación Vial. Cada año se realizan varias ferias comerciales. El sector factura anualmente en Lorca más de 10 millones de euros.

La construcción de este polígono especializado ha posibilitado el traslado de algunos concesionarios de automóviles, talleres y establecimientos vinculados al sector desde su tradicional emplazamiento en la carretera de Granada. Hoy el nivel de ocupación de las parcelas es aún bajo, con lo que su desarrollo va más lento de lo previsto inicialmente.

\subsection{Otros ejes industriales menores}

Otros ejes industriales en el municipio, se encuentran siguiendo otras vías de entrada y salida de Lorca, fundamentalmente tres (Figura 1): las carreteras de Granada, Águilas y Murcia.

En la carretera de Granada, más allá del polígono de Los Peñones y hasta el límite con Puerto Lumbreras (7,5 km.), se alinean a ambos lados empresas industriales aisladas que se dedican a sectores diversos: automoción y transporte, materiales para la construcción, metalurgia y empresas de servicios. La mayor densidad empresarial se alcanza entre Los Peñones y la Ciudad Deportiva y el Hospital General Universitario de Lorca. Destaca la empresa «Cerámicas del Sureste», en la Torrecilla, la única fábrica de tejas y cerámica que queda en Lorca con $332 \mathrm{kw}$. de potencia y 25 trabajadores. El Plan General vigente pretende consolidar este corredor industrial.

La carretera de Águilas, que atraviesa la huerta de Lorca a lo largo de 10 $\mathrm{km}$., se ha convertido en un notable eje industrial. Al margen de las actividades ya reseñadas, destacan las dedicadas al sector agropecuario (hortofrutícolas, ganadería porcina) y las de servicios de restauración. En la zona de Purias, entre la autovía de Águilas y la carretera de Pulpí (Almería), se tramita la creación de un Polígono Industrial similar al de La Hoya sobre una parcela de $818.000 \mathrm{~m}^{2}$.

Por último, la carretera de Murcia es la que menor equipamiento industrial presenta, dado lo accidentado de este acceso a la ciudad por la inmediatez de la sierra de Tercia y el brusco declive del valle. Sólo están presentes algunos talleres mecánicos, artículos de cerámica y empresas del sector del hierro. 
5.8. Industria dispersa: área periurbana y tierras altas

Las actividades industriales y artesanales en el medio rural de Lorca han tenido tradicionalmente un peso específico destacado dados los recursos que ofrece el medio, el aprovechamiento de los tiempos muertos en las faenas agrícolas, la generalización de la energía eléctrica, la existencia de mano de obra abundante, el trabajo a domicilio y un mercado próximo que abastecer. Desde los años sesenta, se intensifica la difusión industrial por el espacio rural lorquino ante la inexistencia de polígonos industriales y la falta de claridad en el planeamiento sobre la instalación de nuevos centros de trabajo fuera del casco urbano. Para Climent (1993) el desarrollo de la industria en áreas rurales obedece al desarrollo endógeno de estos ámbitos gracias a sus recursos, potencialidades, agricultores que acumulan capital y lo invierten en pequeñas industrias de actividad muy especializada y demanda débil, y la existencia de abundante mano de obra.

En el espacio rural de Lorca es preciso distinguir desde el punto de vista geográfico y económico, el área periurbana (valle del Guadalentín) y las tierras altas septentrionales.

El área periurbana de Lorca, donde está instalada la fértil huerta que rodea la ciudad (especializada en la producción de frutas, hortalizas, cereales y en la cría de ganado porcino a gran escala), hay ubicadas decenas de pequeñas empresas de tipo familiar que se alinean siguiendo los caminos y carreteras más importantes, en mezcolanza directa con cientos de viviendas aisladas de primera o segunda residencia, centros de producción ganadera, infraestructuras de regadío, urbanizaciones, eriales... Destacan las industrias ligadas al sector cárnico y de embutidos, alimentación, aceites y grasas, alimentación animal, conservas, extracción de arenas y gravas, materiales para la construcción, confección, y el sector metálico. Las empresas de mayor importancia son: «SAT El Salar» (conservas de frutas y hortalizas, 75 empleados); «Áridos y Transportes» (48 trabajadores); y la empresa «Juan Jiménez García», dedicada al ganado porcino y fabricación de piensos compuestos, que con 36 empleados generó unas ventas en el último año de 115 millones de euros, siendo de las mayores empresas del municipio; parte de sus instalaciones se sitúan en Serrata.

Por otro lado, las tierras altas de Lorca, que se prolongan hacia el Noroeste murciano, forman un territorio de gran extensión $\left(1.000 \mathrm{~km}^{2}\right)$, poco poblado y con graves carencias en cuanto a infraestructuras y servicios; sus habitantes se concentran en pequeñas aldeas y tradicionalmente se han dedicado a la agricultura de secano, a la ganadería extensiva y a varias actividades artesanales. La industrialización es muy débil. Sólo destacan algunas empresas 
dedicadas a la fabricación de alfombras (jarapas, el 90\% de la producción nacional se reparte entre varias empresas familiares de Coy), elaboración de vinos y la extracción de piedra ornamental cuyas canteras se localizan en las proximidades de la sierra del Gigante. De este último sector, destaca la empresa «Mármoles Marín» (1964), que emplea a 65 personas.

Asimismo, en los últimos años, están proliferando en Lorca empresas del sector energético que están aprovechando los elevados niveles de insolación (hasta 3.000 horas de sol al año) para instalar parques solares en el municipio, sobre todo en las tierras altas. En 2008 existían 45 plantas solares que producían 179 megavatios de energía limpia.

\section{CONCLUSIONES}

La industria en Lorca tiene un peso relativo todavía escaso (o insuficiente) en la economía local, lo que supone un lastre para la modernización de la estructura productiva lorquina donde las actividades agrarias y el sector servicios generan buena parte del empleo y la riqueza en el municipio, en muchas ocasiones con empleos poco cualificados y mal remunerados. Se puede afirmar que no se han aprovechado del todo las oportunidades que el extenso territorio de Lorca ofrece, no se han cerrado ciclos productivos industriales de gran potencialidad (calzado, medio ambiente, conservas, moda y confección, recuperación patrimonial...) lo que da lugar a la generación de productos intermedios con escaso efecto multiplicador, y no se ha encauzado desde las diferentes administraciones la atracción de importantes empresas industriales a Lorca y su comarca a pesar de la posición estratégica que ocupa en el corredor Mediterráneo, que se han dirigido a otras zonas (eje Murcia-Cartagena).

La falta de una planificación territorial integral ha derivado la anarquía en el asentamiento de los establecimientos industriales en varios lugares del municipio, con los problemas ambientales y sociales que esto lleva implícito. La experiencia en cuanto a gestión de suelo industrial público y/o privado puede calificarse de exitosa en algunos casos (Saprelorca y La Hoya), de respuesta pública tardía al asentamiento empresarial (Los Peñones), falta de dinámica empresarial (Ciudad de la Automoción), deficiente e inoperativa para la resolución de conflictos territoriales serios (Serrata), y de escasa en la voluntad de crear nuevas zonas industriales en los núcleos rurales más alejados para fomentar la economía endógena. Sería conveniente la instalación en las proximidades de la futura estación del AVE en el barrio de San Diego de un parque tecnológico $(\mathrm{I}+\mathrm{D}+\mathrm{i})$ que genere actividades con alto valor añadido. Ni que decir tiene que la migración de las fábricas de la ciudad a la periferia es un hecho 
natural donde se contraponen muchos intereses urbanísticos y empresariales que ha modificado en profundidad el área periurbana circundante.

El futuro de Lorca pasa, irremediablemente, por el desarrollo ordenado y lógico del sector industrial como un pilar económico más que complemente en épocas de crisis como la actual, al resto de sectores productivos si se quiere reducir el drama del desempleo y aumentar la renta per cápita y la calidad de vida de los ciudadanos.

\section{FUENTES Y BIBLIOGRAFÍA CONSULTADA}

ARANDA GALlego, J. (2010): Evolución reciente y cambios estructurales en el valle del Guadalentín, Confederación Comarcal de Organizaciones Empresariales de Lorca, Lorca, 155 pp.

CÁMARA DE COMERCIO E INDUSTRIA DE LORCA (1991): La economía de Lorca. Situación y perspectiva, Cámara de Comercio e Industria de Lorca, Murcia, 365 pp.

CÁMARA DE COMERCIO E INDUSTRIA DE LORCA (2009): Economía y empresa en los municipios de Lorca y Puerto Lumbreras, Cámara de Comercio e Industria de Lorca (Observatorio Económico), Murcia, 260 pp.

CAPEl SÁez, H. (1968): Lorca, capital subregional, Cámara de Comercio e Industria de Lorca, Lorca, 260 pp.

CARM-CENTRO REGIONAL DE ESTADÍSTICA (2008 a): Anuario estadístico de la Región de Murcia (2008), Consejería de Economía y Hacienda, Dirección General de Economía y Planificación, en línea <www.carm.es/econet> [26 de diciembre de 2010].

CARM-CENTRO REGIONAL DE ESTADÍSTICA (2008 b): Lorca en cifras (2008), Consejería de Economía y Hacienda, Dirección General de Economía y Planificación, en línea <www.carm.es/econet $>$ [26 de diciembre de 2010].

CARM-CONSEJERÍA DE UNIVERSIDADES, EMPRESA E INVESTIGACIÓN (2008): Registro de establecimientos industriales, en línea <www.carm.es> [23 de diciembre de 2010].

CARM-CONSEJERÍA DE FOMENTO Y TRABAJO (1994): Censo de población de 1991 de la Región de Murcia, Tomo I (Murcia, Cartagena y Lorca), Dirección General de Economía y Planificación, Centro Regional de Estadística, Murcia, pp: 514-600.

CARM-INSTITUTO DE FOMENTO (2009): Suelo industrial en la Región de Murcia (2009), Instituto de Fomento de la Región de Murcia (INFO), Murcia.

CARM-SERVICIO REGIONAL DE EMPLEO Y FORMACIÓN (2010): Informes municipales sobre el mercado laboral, Observatorio Ocupacional, Informes de mercado laboral (2005 y 2010), en línea <www.sefcarm.es>, [3 de enero de 2011]. 
CLiment López, E.A. (1993): «La industria y el espacio rural», Geographicalia, $n{ }^{o}$ 30, Universidad de Zaragoza, Zaragoza, pp: 103-111.

FUNDACIÓN BBVA (2010): Estrategias de innovación industrial y desarrollo económico en las ciudades intermedias de España, MÉNDEZ, F. (coor.), Madrid, 611 pp.

GANAU CASAS, J. y Vilagrasa Ibarz, J. (2003): «Las ciudades medias en España: posición en la red urbana y procesos urbanos recientes», en CAPEL SÁEZ, H. Ciudades, arquitectura y espacio urbano, Colección de Estudios Socioeconómicos «Mediterráneo Económico», nº. 3, Instituto Cajamar, Almería, pp: 37-73.

Gil OlcinA, A. (1968): «La ciudad de Lorca. Notas de geografía urbana», Papeles de Geografía, n. ${ }^{\circ}$ 1, Universidad de Murcia, Murcia, pp: 79-110.

Gil OlcinA, A. (1969): «Las industrias de alpargatas y curtidos en Lorca», Cuadernos de Geografía, n. ${ }^{\circ}$ 6, Universidad de Valencia, Valencia, pp: 261-278.

GÓMEZ FAYRÉN, J. (1984): «Tipos de emplazamientos industriales en la Región de Murcia», Papeles de Geografía, n. ${ }^{o}$ 9, Universidad de Murcia, Murcia, pp: 113-144.

GRIS MARTínEZ, J. (1985): «Análisis de los sectores productivos», Lorca, Cámara de Comercio e Industria de Lorca, pp: 137-183 y anexos.

GuiraO, J. (1949): Guía de Lorca, Lorca, 79 pp.

INE (2004): Censo de población y vivienda de 2001, Instituto Nacional de Estadística, en línea <www.ine.es>, [26 de diciembre de 2010].

INE (2010): Padrón municipal de habitantes (1 de enero de 2010), Instituto Nacional de Estadística, en línea <www.ine.es>, [26 de diciembre de 2010].

LA CAIXA (2010): Anuario económico de España (2010), Bases de datos municipal y provincial, La Caixa, en línea <www.anuarieco.lacaixa.comunicacions. com>, [23 de diciembre de 2010].

MAS HERnÁNDEZ, R. (1999): «Periferias urbanas y nuevas formas espaciales», en Domínguez Rodríguez, R.: La ciudad. Tamaño y crecimiento, III Coloquio de Geografía Urbana, Universidad de Málaga, Málaga, pp: 201-234.

MÉNDEZ y otros (1995): «Los espacios industriales», Geografía Humana, Cátedra, Madrid, pp: 587-700.

PRENSA DE LORCA: Diarios La Verdad, La Opinión, Línea, varios años, Archivo Municipal de Lorca, sección de prensa local.

PROMECOSA (1972): Estudio para la programación del desarrollo económico y social del municipio de Lorca para el periodo 1973-1980, Promeconsa, Madrid, 256 pp.

ROMERA FRANCO, J.D. (2002): «Impactos creados por la actividad industrial en el paisaje urbano de Lorca. Situación actual y actuaciones de recuperación», Papeles de Geografía, n. ${ }^{\circ}$ 35, Universidad de Murcia, Murcia, pp: 227-243.

Romera Franco, J.D. (2009): Configuración urbana de Lorca. Paisajes urbanos y marco geográfico, trabajo de investigación, Doctorado de Geografía y 
Ordenación del Territorio, $2 .^{\circ}$ ciclo, Universidad de Murcia, inédito, 130 pp. y 40 láminas gráficas.

Romera Franco, J.D. (2010): «El plan de urbanización y ensanche de Lorca (1952): planteamientos inéditos, realidades y aportaciones arquitectónicas al paisaje urbano actual», Clavis, n. ${ }^{\circ}$ 6, Archivo Municipal de Lorca, Excmo. Ayuntamiento de Lorca, Murcia, pp: 89-166.

Romero Hernández, M. J. e IbÁÑEz Vilches, J.A. (1985): «La ausencia de suelo industrial en Lorca y su influencia en el emplazamiento de las instalaciones industriales», II Reunión de Geografía Industrial, Santiago de Compostela, 11 pp.

Roselló Verger, V.M. (1982): Estudios de Geografía de Murcia, Academia Alfonso X el Sabio, Murcia, pp: 321-340.

SAPRELORCA (2007): Saprelorca (25 aniversario), Saprelorca, Murcia, 95 pp.

SASTRE FERNÁNDEZ, M. (2006): Barrio de San Cristóbal: su vida, sus industrias, sus gentes, Lorca, $421 \mathrm{pp}$.

Segura Artero, P. e Ibáñez Vilches, J.A. (1990): Curtido en Lorca, Cámara de Comercio e Industria de Lorca, Murcia, 164 pp.

Torbado, J. (1994): «Lorca», Pueblos de España, Tribuna de Actualidad, Madrid, pp: 632-635.

ZÁrATE MARTín, A. (1991): El espacio interior de la ciudad, Espacios y Sociedades, n. ${ }^{\circ} 12$, Síntesis, Madrid, 253 pp. 